\title{
Simulation Analysis of Sedimentation Separation of Suspended Solids Sewage in Oil Field Based on COMSOL
}

\author{
Ren $\mathrm{Y} \mathrm{L}^{1, *}$, He S W' ${ }^{1}$, Lei $\mathrm{Q} \mathrm{M}^{2}$, Gao $\mathrm{S}^{1}$, Jiang $\mathrm{M} \mathrm{Z}^{1}$, Zhang $\mathrm{R} \mathrm{J}^{1}$ and Wang $\mathrm{Y}^{1}$ \\ ${ }^{1}$ mechanical science and engineering college of northeast petroleum institute DaQing 163318 China \\ ${ }^{2}$ Commissioning Operation Company of China Petroleum Pipeline Engineering Co., Ltd
}

\begin{abstract}
After oil and water separation, the produced sewage needs to be treated in a series of ways and injected into the ground if it reaches the discharge standard in oilfields. Sedimentation separation is one of the most important process. In order to study the law of settlement, a set of settlement simulation device was set up, and the raw wastewater was extracted from the oil production plant for settlement experiment, and the relevant data were gathered. Comsol software is used to model and analyse the model. Through comparing the calculation results with the experimental data, the velocity and concentration of liquid-solid two-phase medium change rules are concluded, which lays a foundation for further research on efficient treatment of oilfield sewage.
\end{abstract}

\section{Introduction}

Oil field sewage treatment is to reprocess the sewage produced in the development of oil field to make it reach the standard of reinjection or discharge. According to the different direction of the treated water, the treatment process is also different. The most basic treatment process is to inject the raw sewage liquid directly back to the stratum after primary settlement and secondary settlement and reaching the standard after filtration ${ }^{[1]}$. Sedimentation treatment is the core process to remove flocculent suspended solids, and other complex processing processes are based on this to add specific processes such as secondary filtration, aeration, denitrification, dephosphorization and desalination, infiltration, microbial removal, etc. With the gradual increase of water content in oilfield produced fluid, the amount of sewage treatment and the cost of treatment increase accordingly. Therefore, it is necessary to remove the solid suspended particles in sewage in a timely and efficient way to ensure the continuous and stable circulation of oilfield water system ${ }^{[2]}$. Therefore, a set of sewage settlement experimental equipment is established, and the law of sewage settlement and the factors affecting the settlement effect are studied by the method of numerical analysis ${ }^{[3]}$.

\section{Sewage sedimentation test equipment}

The structure of oilfield sewage treatment settling tank mainly includes settling tank, water distribution device, water collection device, oil collection device, heating device, sludge recovery device, and various supporting components, as shown in Figure 1. ${ }^{[4]}{ }^{[5]}$. Oilfield sewage settlement treatment is divided into primary settlement and secondary settlement. The different density of oil, water and solid particles is the main reason for settlement treatment. The primary settlement mainly removes the floating oil and solid particles with larger particle size. In order to separate the oil drops, suspended solids and other impurities with small particle size in the secondary settlement, flocculant is added into the settling tank, and then gravity is used for separation ${ }^{[6]}$.

In order to facilitate the analysis and research, a set of sewage settlement experimental model is designed with reference to the actual oilfield sewage treatment settling tank structure ${ }^{[7]}$, as shown in Figure 2. Figure 2.A is the physical model of the experimental device, which is made of plexiglass to observe the internal settlement process; Figure 2.B is the computer model of the experimental device. The experimental device is designed according to the actual structure of the settling tank in the oilfield, mainly including the inlet pipe, water distribution structure, water collection structure, drainage and oil collection structure ${ }^{[8]}[9]$, with a volume of $0.026 \mathrm{~m}^{\wedge} 3$. The sprinkler head is used in the water distribution plate, which can expand the separation area and reduce the settling time. The specific settlement process is that the oily sewage enters into the water distribution pipe from the water distribution port and into the inner part of the settling tank from the water distribution port. Due to the different densities of oil, water and solid particles, the oil droplets with smaller density move to the oil collecting pan at the top of the settling tank under the action of gravity for a long time, and the solid particles with larger density deposit at the bottom of the settling tank Sludge is sucked out. Due to the pressure change in the settling tank, the relatively clean water enters the water collecting pipe from the water collecting port and finally flows out of the settling tank. The dimensions of each part of the experimental device are shown in Table 1. 


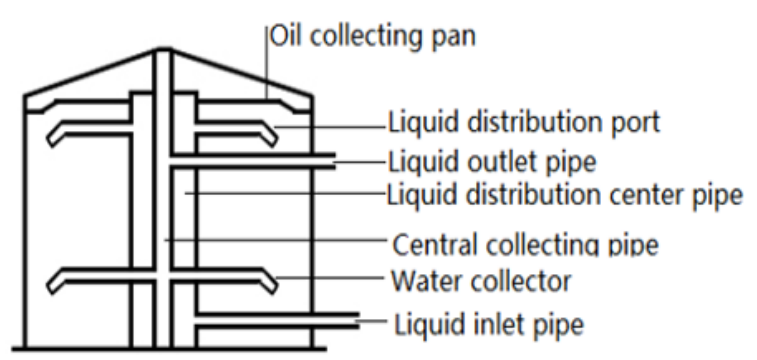

Fig. 1. Settler tank structure diagram

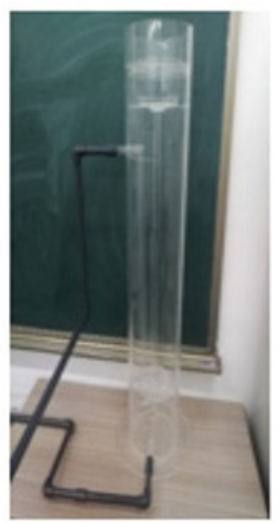

a·Physical-model

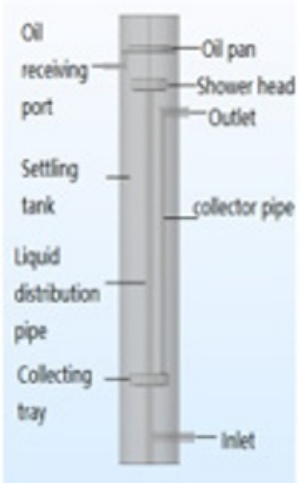

b-Three-dimensional-model
Fig. 2. Experimental model of settling tank

Table 1. Main dimensions of settling tank

\begin{tabular}{|l|l|l|l|}
\hline $\begin{array}{l}\text { Basic } \\
\text { parameters }\end{array}$ & size & $\begin{array}{l}\text { Basic } \\
\text { parameters }\end{array}$ & size \\
\hline $\begin{array}{l}\text { Tank height } \\
(\mathrm{m})\end{array}$ & 0.85 & $\begin{array}{l}\text { Diameter of } \\
\text { collecting pipe } \\
\text { (mm) }\end{array}$ & 10 \\
\hline $\begin{array}{l}\text { Tank diameter } \\
(\mathrm{m})\end{array}$ & 0.2 & $\begin{array}{l}\text { Water } \\
\text { distribution } \\
\text { sprinkler head } \\
\text { hole height } \\
\text { (mm) }\end{array}$ & 5 \\
\hline $\begin{array}{l}\text { Tank capacity } \\
(\mathrm{m} \wedge 3)\end{array}$ & 0.026 & $\begin{array}{l}\text { Diameter of } \\
\text { water } \\
\text { distribution } \\
\text { sprinkler head } \\
\text { (mm) }\end{array}$ & 2 \\
\hline $\begin{array}{l}\text { Inlet pipe } \\
\text { diameter (mm) }\end{array}$ & 20 & $\begin{array}{l}\text { Radius of } \\
\text { collecting hole } \\
\text { (mm) }\end{array}$ & 5 \\
\hline $\begin{array}{l}\text { Diameter of } \\
\text { main water } \\
\text { distribution } \\
\text { pipe(mm) }\end{array}$ & 32 & $\begin{array}{l}\text { Outlet pipe } \\
\text { diameter / } \\
\text { (mm) }\end{array}$ & 12 \\
\hline
\end{tabular}

\section{Build a simulation model}

According to the working principle and structure of the settling tank, its structure can be simplified as follows during the simulation modeling of liquid-solid separation $\left.^{[10}\right]$ :

(1) Ignore the oil collecting pan at the top;

(2) remove unnecessary strengthening components and auxiliary components;
(3) Due to the symmetry of the experimental model, half of the model is taken for liquid-solid separation simulation.

The settlement simulation conditions are simplified as follows ${ }^{[13]}$ :

(1) Ignore oil droplets and other substances in the tank, and only consider water and solid particles

(2) For the convenience of analysis, it is assumed that the particle size of solid particles is uniform.

In fluid analysis, mass conservation equation and energy conservation equation are the most basic and core governing equations.

The mass conservation equation of fluid is:

$$
\frac{\partial \rho}{\partial t}+\frac{\partial(\rho u)}{\partial x}+\frac{\partial(\rho v)}{\partial y}+\frac{\partial(\rho w)}{\partial z}=0
$$

For incompressible flow,

$$
\nabla \cdot U=0
$$

The energy conservation equation is:

$$
\left\{\begin{array}{l}
\frac{\partial u}{\partial t}+\operatorname{div}(u U)=\operatorname{div}(\text { vgradu })+\frac{S_{u}}{\rho}-\frac{\partial p}{\rho \partial x} \\
\frac{\partial v}{\partial t}+\operatorname{div}(v U)=\operatorname{div}(\text { vgradv })+\frac{S_{v}}{\rho}-\frac{\partial p}{\rho \partial y} \\
\frac{\partial w}{\partial t}+\operatorname{div}(w U)=\operatorname{div}(\text { vgrad } w)+\frac{S_{w}}{\rho}-\frac{\partial p}{\rho \partial z}
\end{array}\right.
$$

Wherein: $v$ is kinematic viscosity, $\mathrm{Su}, \mathrm{Sv}, \mathrm{Sw}$ are the three generalized source terms of the momentum equation. For incompressible fluid with constant viscosity, the three generalized source terms are all 0 .

According to the formula of Reynolds number[11]:

$$
R e=\frac{\rho u d}{\mu}
$$

Wherein, $\mu$ is the dynamic viscosity; $\rho$ is density; $u$ is the velocity of the fluid; $d$ is hydraulic equivalent diameter.

The Reynolds number $R e \approx 2300$ is calculated, which belongs to the turbulence with low Reynolds number.

Turbulence intensity is calculated as follows:

$$
I \equiv \frac{\mu^{\prime}}{\bar{\mu}} \cong 0.16\left(R e_{D_{H}}\right)^{-\frac{1}{8}}
$$

Wherein, $\mu^{\prime}$ is turbulent pulsating velocity; $\bar{\mu}$ is the average turbulence velocity; $R e_{D_{H}}$ is the Reynolds number calculated according to hydraulic diameter. The turbulence intensity $\mathrm{I}=5 \%$ of the simulation model is calculate.

The RNGk- $\varepsilon$ turbulence model is selected to calculate the Reynolds number and turbulence intensity. The turbulence model has strong convergence and good adaptability to the grid. Liquid-solid mixture belongs to two-phase flow. In this paper, a two-phase flow mixture model is selected to calculate the dynamic change process of the volume fraction of solid particles in the dispersed phase.

The mixture model in the two-phase flow model is selected, and the turbulence model is selected as RNGk- $\varepsilon$ turbulence model. The mixture model is combined with the RNGk- $\varepsilon$ turbulence model, and the equations are sort out as follows: 


$$
\begin{aligned}
\rho \frac{\partial j}{\partial t}+\rho(j \cdot \nabla) j+ & \left(\rho_{d}-\rho_{c}\right)\left(j_{s l i p} \cdot \nabla\right) j \\
& =\nabla \cdot[-p l+K]-\nabla \cdot K_{m} \\
& +F_{m}+\rho g+F
\end{aligned}
$$

Wherein:

$$
\nabla \cdot j=0 ; \quad K=\left(\mu+\mu_{T}\right)\left(\nabla j+(\nabla j)^{T}\right) ; \quad K_{m}=\left(\rho_{c}+\right.
$$$$
\left.\rho_{d}-\rho\right) u_{s l i p} j^{T}{ }_{\text {slip }} ; \rho=\rho_{d} \emptyset_{d}+\rho_{c}\left(1-\emptyset_{d}\right)
$$$$
\frac{\partial \emptyset_{d}}{\partial t}+j \cdot \nabla \emptyset_{d}+\nabla \cdot j_{\text {slip }}=\nabla \cdot\left(D_{m d} \nabla \emptyset_{d}\right)-\frac{m_{d c}}{\rho_{d}}
$$$$
\emptyset_{d}=\text { phid } ; N_{\emptyset d}=j_{d}-D_{m d} \nabla \emptyset_{d} ; j_{d}=\emptyset_{d} u_{d} ; u_{d}=
$$$$
j+u_{\text {slip }}\left(1-\emptyset_{d}\right) ; D_{m d}=\frac{\mu_{T}}{\rho \sigma_{T}} \text {. }
$$$$
\rho \frac{\partial k}{\partial t}+\rho(j \cdot \nabla) k=\nabla\left[\left(\mu+\frac{\mu_{T}}{\sigma_{k}}\right) \nabla k\right]
$$$$
+P_{k}-\rho \epsilon
$$

$$
\begin{aligned}
\rho \frac{\partial \epsilon}{\partial t}+\rho(j \cdot \nabla) \epsilon= & \nabla\left[\left(\mu+\frac{\mu_{T}}{\sigma_{\epsilon}}\right) \nabla \epsilon\right] \\
& +C_{\epsilon 1} \frac{\epsilon}{k} P_{k}-C_{\epsilon 2} \rho \frac{\epsilon^{2}}{k}
\end{aligned}
$$

wherein: $\epsilon=e p ; \mu_{T}=\rho C_{\mu} \frac{k^{2}}{\epsilon}$

In equations (9) to (11): $\rho$ is the concentration, $j$ is the velocity field of the mixture, $\rho_{d}$ is dispersed phase concentration, $\rho_{c}$ is continuous phase concentration, $j_{\text {slip }}$ is slip flux, $\mathrm{k}$ is turbulent kinetic energy, $\mathrm{F}$ is volume force, $K_{m}$ is diffusion stress tensor, $\emptyset_{d}$ is volume fraction of dispersed phase, $e p$ t is urbulence dissipation rate, $D_{m d}$ is turbulent dispersion.

\section{Solving the simulation model}

\subsection{Geometric model, oil-water parameters and boundary conditions}

Using the LIVEINK function of COMSOL, the threedimensional graphics of the settlement device in SolidWorks are imported into COMSOL geometry, and the density of water and solid particles, the dynamic viscosity of water and the diameter of solid particles are added respectively. The volume fraction of solid particles is set as 0.005 , and the above initial parameters are all from a sewage treatment station in Daqing oilfield. In order to improve the convergence, a step function is added to slowly increase the inlet speed to $0.1 \mathrm{~m} / \mathrm{s}$, all wall conditions are set as no slip, pressure constraint points are added, gravity is applied on all domains, and the simulation time is set as $2 \mathrm{~h}$. The relevant parameters are set as shown in Table 2:

Table 2. Key parameters of simulation

\begin{tabular}{|l|l|}
\hline name & number \\
\hline The density of the water phase & 990 \\
\hline Solid density & $1300 \mathrm{~kg} / \mathrm{m}^{3}$ \\
\hline Dynamic viscosity of aqueous phase & $0.00126 \mathrm{~Pa} . \mathrm{s}$ \\
\hline Solid diameter & $1 \mathrm{E}-4 \mathrm{~m}$ \\
\hline Inlet velocity & $0.1 \mathrm{~m} / \mathrm{s}$ \\
\hline Initial volume fraction of particles & 0.008 \\
\hline
\end{tabular}

\subsection{Mesh partitioning and checking}

In the COMSOL multi-physics simulation, liquid-solid separation belongs to the fluid flow module, and the mixture model and the RNGk- $\varepsilon$ turbulence model are selected. The slip model Hadamard-Rybczynski is selected, and the study method is added as transient study. The physical field control function of COMSOL is used to automatically generate grids and check the unit quality of the generated grids, as shown in Figure 3. The minimum grid mass is 0.1715 , which is 0.1 more than the minimum cell mass required for calculation. The average grid mass is 0.6559 , and the total grid volume is $1.313 \mathrm{E} 7 \mathrm{~mm}^{\wedge} 3$.

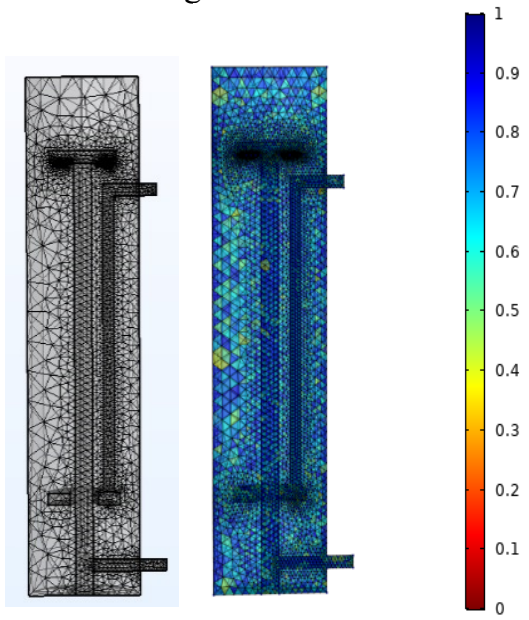

Fig. 3. Grid division and grid quality of settling tank

\section{Analysis of simulation results}

After the simulation calculation complete, half of the simulation results are converted into the whole simulation image by using the three-dimensional mirror function of COMSOL results processing. The simulation results are analyzed as follows.

\subsection{Direction of flow line in settling tank}

The mixed logistics diagram is shown in Figure 4. According to the direction of the flow line, the mixture of water and solid particles flows into the central distribution pipe through the inlet and into the settling tank through the sprinkler head. With the rising water level in the settling tank and increasing pressure, it flows into the collecting pipe through the collecting tray and the collecting nozzle. This is consistent with the actual sewage treatment conditions. The flow line near the sprinkler head and the water collecting nozzle is more dense, the flow rate is unstable, and it is easy to form eddy current or settlement dead zone, which is adverse to the liquid-solid separation in the settling tank. 


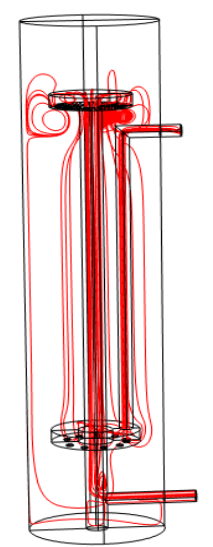

Figure 4. Flow line in settling tank

\subsection{Analysis of velocity field in settling tank}

The velocity field in the settling tank is shown in Figure 5. It can be seen from the simulation results that the velocity is unstable near the sprinkler head and the water collecting port. The velocity field inside the settling tank is downward, and the heavier solid particles downward faster because of the different densities of water and solid particles. The velocity of the collecting pipe and distribution pipe is obviously different from that of the liquid-solid separation area of the settling tank. Due to the small volume of the settling tank and the small inflow velocity of the inlet, the velocity of the liquid-solid settling area in the settling tank is small and there is no obvious change. Different from oil-water separation, solid particles are independent in the process of sinking. The oil droplets coalesce together in the process of rising, so the separation velocity of oil and water will increase significantly, while the separation velocity of liquid and solid is relatively stable.

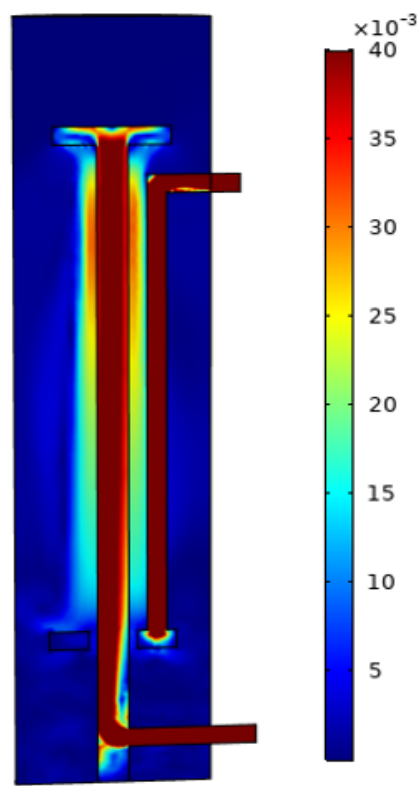

Figure 5. Velocity field distribution in settling tank

\subsection{Concentration field analysis in settling tank}

Figure 6. shows the variation rule of solid particles in the settling tank with time and the height of the settling tank.

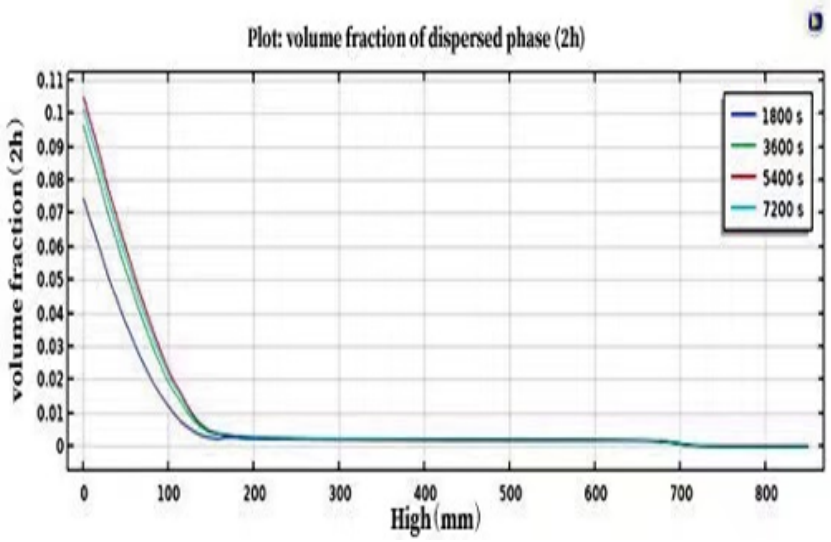

Figure 6. Distribution of solid particle concentration with time and height

Initial volume fraction of solid particles is 0.005 , after the settlement of $1.5 \mathrm{~h}$, the volume fraction of solid particles tend to be stable. The mixture flows from the sprinkler head to the bottom of the settling tank, so there are no solids at the top of the settling tank. Solid particles are concentrated at the bottom of the settling tank, and there are only a few solid particles in the middle of the settling tank, which again shows that the settling effect is obvious.

After settling separation for 2 hours, the concentration distribution of solid particles in the settling tank (volume fraction of solid particles) is shown in Fig.7. As can be seen from the figure, solid particles are concentrated at the bottom of the settling tank, and the maximum volume fraction reaches 0.13 . There are also a small amount of solid particles around the catchpan, which is due to the large and unstable flow rate near the catchpan's inlet, which has a certain influence on the settling of solid particles.
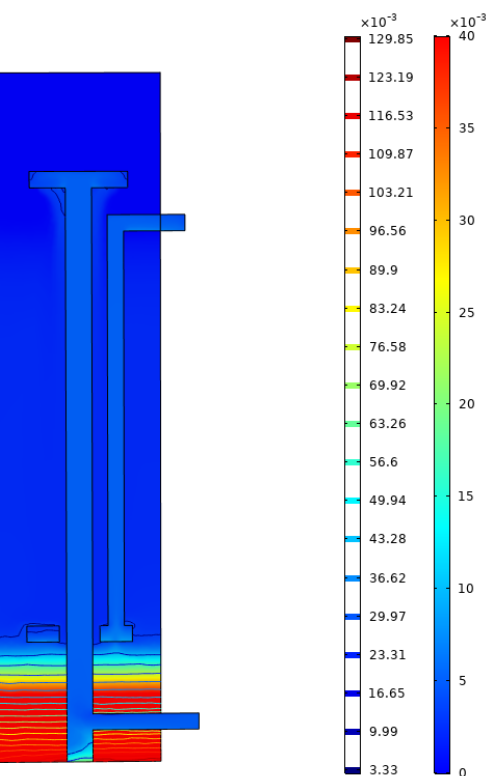

Figure 7. Solid particle concentration distribution after $2 \mathrm{~h}$ 


\subsection{Liquid-solid separation rate}

At the initial time of simulation, the volume fraction of solids is 0.005 , the settling time is $2 \mathrm{~h}$, the sewage inlet velocity is $0.1 \mathrm{~m} / \mathrm{s}$, the sludge collection height of the settling tank is $0.15 \mathrm{~m}$, and the average volume fraction of solid particles at the bottom of the settling tank is 0.06 .

$$
\text { By the formula } \quad \eta=\frac{v_{1}}{v_{0}}
$$

Wherein, $v_{1}$ is the volume of solid particles at the bottom of the settling tank; $v_{0}$ is the total volume of solid particles flowing through the settling tank.

After calculation, the liquid-solid separation efficiency of the settling tank is 0.65 , and the settling efficiency is consistent with the next settling liquid-solid separation efficiency under the actual working condition.

\section{Settler tank test results}

In order to comparing with the results of simulation separation validation, sample the same as the initial data simulation of sewage sedimentation tank for settling experiment in the laboratory, settling time and simulation analysis of the same time, after the completion of the settlement to test the distribution of solid particles, the sedimentation tank bottom, is $80 \mathrm{~mm}$ from the bottom, is $100 \mathrm{~mm}$ from the bottom of the three locations is used to detect the volume fraction, volume fraction of $0.1,0.04$ and 0.02 respectively, the actual settlement results are basically the same as the results of simulation, compared the results as shown in table 3 .

Table 3. Comparison of settlement results between simulation and laboratory settlement tank

\begin{tabular}{|l|l|l|}
\hline & $\begin{array}{l}\text { Simulation } \\
\text { results }\end{array}$ & $\begin{array}{l}\text { Settlement } \\
\text { experiment } \\
\text { results }\end{array}$ \\
\hline The bottom & 0.15 & 0.1 \\
\hline $\begin{array}{l}\text { From the } \\
\text { bottom of the } \\
80 \mathrm{~mm}\end{array}$ & 0.043 & 0.04 \\
\hline $\begin{array}{l}\text { From the } \\
\text { bottom of the } \\
100 \mathrm{~mm}\end{array}$ & 0.02 & 0.02 \\
\hline
\end{tabular}

\section{Conclusion}

Through the analysis of oilfield sewage sedimentation tank process, established a set of indoor simulation experiment device, using the finite element analysis software COMSOL on the sedimentation separation simulation, analyzed the velocity field and concentration field in the sedimentation tank simulation of distribution, sampling by experiments on the measurement and compares the simulated values and measured values, the results show that the finite element analysis results and actual measurement results, correct COMSOL numerical analysis model and the settlement method. The research method is helpful to provide guidance for the optimization of settlement separation structure and process.

\section{Acknowledgments}

Thanks for the support from the Funding of US-China Clean Energy Research Center Joint Work Plan for Research Projects on Water Energy Technologies: "Non Traditional Water Resources Treatment and Management"(2018YFE019600).

\section{References}

1. Chen P, Chen Z X and Bai C Y. Current status and understanding of produced water treatment technology in DaQing oilfield [J]. Oil-Gas Field Surface Engineering, 2018, 37(07):19-24.

2. He Y H. New technology of produced water treatment in Daqing oilfield [J]. Oil-Gas Field Surface Engineering, 2013, 32(10):79-80.

3. Su J W, Wang L, Liu Y Q. Numerical simulation of two-phase flow in secondary sedimentation tank and the influence of mixed liquid rheological properties [J]. Technology of Water Treatment, 219, 45(07):47$53+59$.

4. SUN D F. Research on Separation Characteristics and Structure Optimization of Vertical Settling Tank [D]. Northeast Petroleum University, 2016.

5. DONG W T. Research on Oil and Water Separation Characteristics and Structure Optimization in Settlement Tank [D]. Northeast Petroleum University, 2013.

6. WANG X Experiment and Comparison of Sludge Removal Process in Sewage Settlement Tank [J]. OilGas Field Surface Engineering, 2015, 34(06):25-27.

7. Zhang J . Simulation and software development of wastewater treatment process [D]. Dalian University of Technology, 2011.

8. Wang J Z, Li L, Shi H X, Qiao F L and Liu M O. Research on treatment measures of produced water quality in oilfield [J]. Oil-Gas Field Surface Engineering, 202, 39(11):44-47. (in Chinese)

9. Wei L P. Optimization of produced water treatment process and application of integrated device in Changqing Oilfield [J]. Energy Conservation and Environmental Protection, 2019(08):109-110.

10. Zhou Z Y. Discussion on the application of oilfield produced water treatment technology $[\mathrm{J}]$. Chemical Industry Management, 2020(15):94-95.

11. Zhang J J, He W, Li B L, Jia R. A brief analysis of the process and key technologies of wastewater treatment facilities [J]. Resources Conservation and Environmental Protection, 2020(03):104.

12. Zhang S Hand LIU Z Z. Design of gravity settling sludge thickening tower [J]. INDUSTRIAL WATER TREATMENT, 1995(06):32-33.

13. Qiao F L. Chemical Industry Management, 2019(17):198. (in Chinese). 